\title{
Electronic Health Record Documentation Patterns of Recorded Primary Care Visits Focused on Complex Communication: A Qualitative Study
}

\author{
Laura Prater $^{1}$ Anthony Sanchez ${ }^{2}$ Gabriella Modan ${ }^{3}$ Jennifer Burgess ${ }^{3}$ Kim Frier $^{4}$ Nathan Richards ${ }^{3}$ \\ Seuli Bose-Brill ${ }^{1}$
}

${ }^{1}$ Division of General Internal Medicine, The Ohio State University Wexner Medical Center, Grandview, Ohio, United States

${ }^{2}$ College of Medicine, The Ohio State University, Columbus, Ohio, United States

${ }^{3}$ Department of English, The Ohio State University, Columbus, Ohio, United States

${ }^{4}$ Division of Palliative Medicine, The Ohio State University Wexner Medical Center, Columbus, Ohio, United States

\author{
Address for correspondence Laura Prater, PhD, MPH, MHA, Division \\ of General Internal Medicine, The Ohio State University Wexner \\ Medical Center, 895 Yard Street, Grandview, OH 43212, United States \\ (e-mail: laura.prater@osumc.edu).
}

Appl Clin Inform 2019;10:247-253.

\section{Abstract}

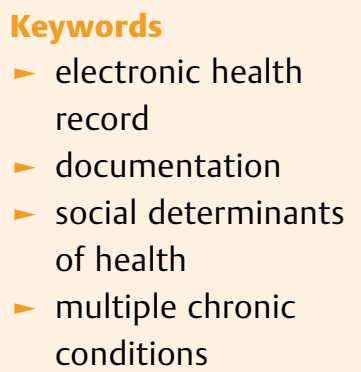

Background In a time-constrained clinical environment, physicians cannot feasibly document all aspects of an office visit in the electronic health record (EHR). This is especially true for patients with multiple chronic conditions requiring complex clinical reasoning. It is unclear how physicians prioritize the documentation of health information in the EHR.

Objective The goal of this study is to examine documentation tradeoffs made by physicians when caring for complex patients by comparing the content of office visit conversations with resulting EHR documentation.

Methods We used grounded theory method of qualitative analysis to assess emergent themes in the transcripts of 10 office visits, and then compared the themes to documentation in the EHR. Differences between discussion and subsequent documentation of social and emotional health topics and each of the other key categories were compared using the Wilcoxon signed-rank test.

Results The categories that emerged included "chronic conditions," "acute/new problems," "disease prevention," and "social and emotional health." We found that when social and emotional topics were discussed in the office visit, it was documented in the medical record only $30.6 \%$ of the time. Chronic conditions, acute/new problems, and disease prevention were documented in the EHR between 87.5 and $91.7 \%$ of the time after discussion. The differences between discussion and documentation of social and emotional topics were significantly greater than the differences for chronic conditions, acute/new problems, and disease prevention (all $p<0.05$ ).

Conclusion Social and emotional factors, while extremely relevant to health management, are less likely than medical concerns to be documented after discussion in an office visit. This lack of documentation may hinder interdisciplinary communication between teams informing individualized therapeutic decisions during acute care handoffs, such as outpatient to inpatient care. received

November 21, 2018

accepted after revision

February 13, 2019 (c) 2019 Georg Thieme Verlag KG Stuttgart · New York
DOI https://doi.org/

$10.1055 / \mathrm{s}-0039-1683986$. ISSN 1869-0327. 


\section{Background and Significance}

The electronic health record (EHR) is a comprehensive and longitudinal health record including patient data on demographics, progress notes, problems, medications, medical history, and other detailed medical information. ${ }^{1}$ The EHR was, in part, developed to help improve communication between providers, and in this role it has shown mixed results in terms of cost savings and improved quality outcomes. ${ }^{2-5}$ Despite limitations arising from interoperability challenges, the EHR still serves as the main platform for communication in interdisciplinary care teams and between physicians, especially when these providers are spread out over different locations. ${ }^{6}$

Despite the EHR's usefulness, many providers find documentation requirements (complicated by additional regulatory demands) have increased, occupying almost half of a physician's time. ${ }^{7}$ Despite documentation becoming more comprehensive with the switch from paper to electronic medical records, it has also likely increased the amount of time spent documenting. ${ }^{8-10}$ The problem is amplified when treating patients with chronic conditions, for whom providing guideline-based care in all scenarios would take more time than the practicing physician has available for patient care. ${ }^{11}$ Considering $67.7 \%$ of patients 65 years or older have at least two chronic conditions in 2015, this issue is particularly significant with the aging U.S. population. ${ }^{12}$

In addition to the competing time priorities found in caring for the complex patient, the provider must also take care to avoid fragmentation due to situations such as having multiple providers, discontinuation of insurance coverage, and receiving services across multiple settings of care, all of which have been shown to affect communication and patient care outcomes. ${ }^{13,14} \mathrm{~A}$ fragmented system can contribute to the loss of important information between providers, leading to "depersonalization" of care as well as medical errors, gaps in clinical decision-making, and reductions in patient adherence. ${ }^{15-17}$ In an effort to mitigate communication gaps resulting from fragmented care, physicians caring for patients in different medical environments (e.g., inpatient, subspecialty, and primary care) increasingly rely on EHR documentation from other disciplines to gain a more comprehensive picture of a patient's history to guide health management decisions. ${ }^{18,19}$

Due to additional regulatory demands and trends impacting medical practice, EHR documentation has become timeintensive; it can take physicians three times longer to record patient information in the EHR compared with paper charts. ${ }^{8}$ Time demands of EHR documentation, the growth in prevalence of complex, multimorbid disease, and an increased focus on clinician productivity leading to shorter visit times, limits the ability of physicians to comprehensively document all aspects of the visit. ${ }^{20}$ These limitations result in a system where individual clinicians exercise judgment on priority areas necessitating documentation. Current literature inadequately describes which aspects of office visits physicians choose to synthesize into a coherent story in EHR documentation. This study was designed to explore this gap in knowledge by comparing office visit conversations with resultant EHR documentation.

\section{Objective}

The goal of this study is to compare the content of recorded office visit conversations between clinicians and patients with complex chronic disease with resulting EHR documentation to observe how clinicians prioritize discussed topics for documentation.

\section{Methods}

This study involves the qualitative analysis of the transcripts and recordings from 10 complex patient-physician encounters gathered from primary care practices within a large Midwestern medical center exclusively using the Epic EHR system, in 2016. Previous studies investigating similar qualitative communications data have similarly sized study samples. $^{21,22}$ The concept of saturation, when no new information is gleaned from the data, guided our decision that 10 transcribed clinical encounters were adequate to address our aim. ${ }^{23}$ This study's 10 clinical encounters focused on complex cases with multimorbid disease because these time-intensive encounters resulted in content-rich data for analysis.

Each of the 10 encounters was audio recorded and subsequently copied using detailed transcription. Accuracy was verified by spot-checking transcripts to the recorded encounters at 2-minute intervals by a member of the research team not responsible for transcription. The clinical transcripts were analyzed using elements of grounded theory method of qualitative data analysis as described by Glaser and Strauss. ${ }^{24}$ Specifically, transcripts were read in their entirety and clinical topics were coded as emergent themes. Following coding, categories based on these themes were constructed and examples were defined for each theme. Next, the research team pulled each encounter's corresponding progress note from the EHR, conducted a content analysis, and compared the results of the transcript coding to the progress notes, using the emergent themes from the transcripts. Percentage agreement was calculated between the content analysis from the transcripts and the documentation in the EHR within each general theme. Additional areas of the chart, such as the social history tab, were also searched to ensure complete analysis of chart content from the relevant office visit. After individual analysis, the two team members met to discuss, compare, and contrast their findings and impressions of both data sources. In instances of disagreement between analysts regarding the appropriate theme, agreement was eventually achieved through brief discussion. Microsoft Word and Excel 2016 were used for transcription and coding.

We also quantitatively assessed the paired differences between discussion and subsequent documentation in each of the key categories. The differences between social/ emotional discussion and documentation were compared with the differences between the discussion and documentation of chronic conditions, preventive care, and acute conditions for each of the patient/provider encounters using the Wilcoxon signed rank test. The Wilcoxon signed rank test is a nonparametric method often used to compare two 
samples which are not independent and which may violate the normality assumption of parametric methods. ${ }^{25}$ Stata IC/ version 14.2 was used for the analysis. ${ }^{26}$

Institutional Review Board approval was obtained prior to the commencement of the study. Written informed consent was obtained from both the physician and patient prior to the recorded visit. Digital files of the transcribed interviews were kept electronically and were securely stored so that only appropriate members of the research team were able to access the data.

\section{Results}

The study population consisted of 10 unique patient/provider pairs, as is seen in - Table 1. Of the patients, four were male and six female, with an average age of 59 years old. Patients had an average of 14 chronic problems and had an average of 12 prescribed medications in their record. Of the 10 encounters, 6 providers were female and 4 providers were male; 9 of these providers were medical doctors and 1 was a nurse practitioner. All providers specialized in internal medicine.

The categories that emerged included "chronic conditions," "acute/new problems," "disease prevention," and "social and emotional health." The "chronic conditions" category is used to classify any discussion related to a long-term condition that had been previously established in past visits as an ongoing problem. Diseases that fall into this category might include diabetes, hypertension, and hyperlipidemia. "Acute/new problems" refers to discussions of either recent problems of which the provider was previously unaware, or a complaint that was treated and subsequently resolved. "Disease prevention" is used to classify discussions regarding vaccinations and screening tests, such as a colonoscopy or a pneumonia vaccine. Finally, "social and emotional health" classifies a variety of other discussions, particularly those that are focused on a patient's social and work life, emotions, preferences, finances, and other psychosocial topics.

Interestingly, we found that the majority of "social and emotional health" discussions went undocumented. On the other hand, discussions regarding chronic conditions, new and acute problems, and disease prevention were consistently documented. Across the 10 encounters, a total of 137 topics were discussed between the patients and providers, averaging 14 topics per encounter. Of 73 total "chronic conditions" topics, 66 (90.4\%) were documented in the

Table 1 Patient/provider demographics

\begin{tabular}{|l|l|}
\hline \multicolumn{2}{|l|}{ Patient/Provider demographics } \\
\hline Provider sex & 6 female; 4 male \\
\hline Patient race & 9 white; 1 African American \\
\hline Patient sex & 4 male; 6 female \\
\hline Average patient age & 59 \\
\hline $\begin{array}{l}\text { Average number of } \\
\text { chronic conditions }\end{array}$ & 14 \\
\hline $\begin{array}{l}\text { Average number of } \\
\text { medications }\end{array}$ & 12 \\
\hline
\end{tabular}

Table 2 Number of chronic, acute, preventive, and social/ emotional topics documented after discussion (documented/ discussed)

\begin{tabular}{|l|l|l|l|l|}
\hline $\begin{array}{l}\text { Patient/ } \\
\text { Provider } \\
\text { pair }\end{array}$ & $\begin{array}{l}\text { Chronic } \\
\text { conditions }\end{array}$ & $\begin{array}{l}\text { Acute/ } \\
\text { New } \\
\text { problems }\end{array}$ & Preventive & $\begin{array}{l}\text { Social- } \\
\text { emotional } \\
\text { health }\end{array}$ \\
\hline 1 & $2 / 3$ & $2 / 2$ & $0 / 0$ & $1 / 4$ \\
\hline 2 & $3 / 3$ & $3 / 3$ & $0 / 0$ & $1 / 2$ \\
\hline 3 & $12 / 13$ & $0 / 0$ & $2 / 2$ & $1 / 1$ \\
\hline 4 & $13 / 14$ & $0 / 0$ & $1 / 2$ & $2 / 6$ \\
\hline 5 & $10 / 10$ & $5 / 5$ & $0 / 0$ & $1 / 3$ \\
\hline 6 & $3 / 4$ & $0 / 1$ & $0 / 0$ & $0 / 5$ \\
\hline 7 & $8 / 9$ & $3 / 3$ & $1 / 1$ & $2 / 4$ \\
\hline 8 & $3 / 4$ & $2 / 2$ & $3 / 3$ & $3 / 7$ \\
\hline 9 & $7 / 7$ & $1 / 2$ & $1 / 1$ & $0 / 2$ \\
\hline 10 & $5 / 6$ & $0 / 1$ & $0 / 0$ & $0 / 2$ \\
\hline Total & $66 / 73$ & $16 / 19$ & $8 / 9$ & $11 / 36$ \\
& $(90.4 \%)$ & $(84.2 \%)$ & $(88.9 \%)$ & $(30.6 \%)$ \\
\hline
\end{tabular}

encounter's corresponding progress note. A similarly high percentage of topics were documented for "acute/new problems" and "disease prevention"; results showed 16 out of 19 (84.2\%) and 8 out of 9 (88.9\%) discussions were documented in these categories, respectively. In contrast, of the 36 "social and emotional health" topics discussed, only 11 (30.6\%) of these details were documented in the corresponding progress note. These results are described at the encounter level in $=$ Table 2.

Results from the Wilcoxon signed rank test tested the null hypothesis that the median difference among pairs is equal to zero. We reject the null hypothesis and conclude that the median difference between social/emotional documentation and discussion was significantly greater than the median differences between the discussion and documentation of chronic conditions $(z=2.57 ; p<0.05)$, disease prevention $(z=2.92 ; p<0.01)$, and acute conditions $(z=2.78$; $p<0.01$ ) across all encounters. Transcribed examples of discussions corresponding to each of the four categories are present in -Table 3 .

-Table 4 displays the total time spent discussing each topic across all 10 encounters, as well as the average time spent discussing each topic. On average, chronic topics were discussed for the longest amount of time per encounter (9:07), followed by similar durations for preventive topics (5:59) and social/emotional topics (5:49), and finally acute topics (3:33).

\section{Discussion}

Our primary finding that social and emotional topics are less likely to be documented after discussion, relative to acute, chronic, and/or preventative topics, is not consistent with documenting a holistic history of the patient's health. We found that physicians were more likely to focus on the documentation of clinical complaints and less on social and 
Table 3 Examples of topics addressed in office visits, by category

\begin{tabular}{|c|c|c|c|}
\hline Topic & Example 1 & Example 2 & Example 3 \\
\hline Chronic & $\begin{array}{l}\text { Doctor: "I actually would be } \\
\text { interested to have you check your } \\
\text { blood sugars two hours after your } \\
\text { meals and see where it's at" } \\
\text { Patient: "Okay" }\end{array}$ & $\begin{array}{l}\text { Patient: “Metformin- it gives me } \\
\text { some gas, it's not horrible, I have } \\
\text { to watch my carbohydrates or I get } \\
\text { gas" }\end{array}$ & $\begin{array}{l}\text { Patient: “...headaches are rare now } \\
\text { which I'm very thankful for...” }\end{array}$ \\
\hline Acute & $\begin{array}{l}\text { Doctor: "You had mentioned you } \\
\text { were having some new shortness } \\
\text { of breath"Patient: "Yeah" }\end{array}$ & $\begin{array}{l}\text { Patient: "My finger is pink, it's } \\
\text { tender" }\end{array}$ & $\begin{array}{l}\text { Patient: "It started Saturday night I } \\
\text { didn't feel...I just felt really tired, } \\
\text { and then Sunday I woke up... I was } \\
\text { really sick..." }\end{array}$ \\
\hline Preventative & $\begin{array}{l}\text { Doctor: "Also you need your third } \\
\text { Hep B vaccination"Patient: "Okay" }\end{array}$ & $\begin{array}{l}\text { Doctor: "Just like the flu vaccine } \\
\text { there are always potential side } \\
\text { effects"Patient: "Can we wait"- } \\
\text { Doctor: "Of course" }\end{array}$ & $\begin{array}{l}\text { Doctor: "There's a recommenda- } \\
\text { tion for a new pneumonia vaccine, } \\
\text { it's not new on the market,but new } \\
\text { for older folks" }\end{array}$ \\
\hline $\begin{array}{l}\text { Social/ } \\
\text { Emotional }\end{array}$ & $\begin{array}{l}\text { Patient: "I mean I am not kidding } \\
\text { you like last weekend I literally lay } \\
\text { in bed and I cried I'll bet you for } \\
\text { five-six hours straight" }\end{array}$ & $\begin{array}{l}\text { Patient: (on suicidal ideation) } \\
\text { "Yeah the mental thing too, it's like } \\
\text { there's days where I honestly...I } \\
\text { thought about it" }\end{array}$ & $\begin{array}{l}\text { Patient: "I think we're gonna lose } \\
\text { our health insurance and our pre- } \\
\text { scription coverage through (com- } \\
\text { pany name) we got a letter the } \\
\text { other day..." }\end{array}$ \\
\hline
\end{tabular}

Table 4 Total and average time spent discussing each topic

\begin{tabular}{|l|l|l|l|l|}
\hline & Social/Emotional (min:s) & Acute (min:s) & Chronic (min:s) & Preventative (min:s) \\
\hline Total time (range) & $58: 10(0: 31-11: 28)$ & $35: 28(0: 00-8: 29)$ & $91: 11(2: 11-16: 03)$ & $29: 45(0: 00-13: 24)$ \\
\hline Average time per encounter & $5: 49$ & $3: 33$ & $9: 07$ & $5: 59$ \\
\hline
\end{tabular}

emotional factors, which have been shown to drive a patient's health care decision making. ${ }^{27}$ Social determinants of health have a significant impact on the management of chronic and acute conditions, making them especially relevant for care planning. ${ }^{28}$ Patients with multiple chronic conditions are very likely to have social determinants that could impact the development and management of their health status. ${ }^{29}$ For example, patients living in more socioeconomically deprived areas not only had a higher prevalence of mental health disorders such as depression, but also increased numbers of physical health disorders and multimorbidity. ${ }^{20}$

The Institute of Medicine (IOM) recommends that EHRs capture information for 10 domains of social determinants of health-4 of which are already regularly collected (race, alcohol use, tobacco use, and address) ${ }^{30}$ Stage three of the Center's for Medicare and Medicaid Services EHR Meaningful Use program also used the IOM report to develop standards for health care providers on the collection of social and demographic information in the EHR to establish meaningful use of an EHR. ${ }^{30}$ With substantial growth in value-based purchasing and alternative models of care such as the Patient-Centered Medical Home (PCMH), the capture of social determinants for patients will continue to grow in importance.

As the Meaningful Use program moves forward with updated goals reflected in their new title (the "Promoting Interoperability" program), there will be an increased focus on patient portal use and interoperability. ${ }^{31}$ Providers must adapt by assessing a patient's readiness and willingness to communicate via portal and by documenting relevant social characteristics in the EHR. Training, engaging caregivers, and increasing access to technology in public settings have all been identified as potential avenues for improving access and use of patient portals. ${ }^{32}$ Engaging in these strategies with a patient will require a comprehensive assessment of their social and emotional well-being as well as their acceptance of the technology. Documentation of these conversations will be critical so that all members of the care team are able to engage in care planning for the patient as this relationship becomes more dependent on technology.

Based on the results from our study, clinicians generally did not prioritize the documentation of social information in the studied patient encounters, despite the fact that they spend more time discussing them than they do acute topics, and similar amounts of time discussing preventive topics. The results of our duration analysis for each topic show that clinicians are prioritizing communication regarding social and emotional topics, but not documentation. The root causes behind this incongruity are not yet clearly defined in the literature. Existing research shows that physicians tend to have negative perceptions regarding the Meaningful Use/Promoting Interoperability program because of increased time demands for documentation. ${ }^{33}$ National, multisite studies have shown that physician documentation burdens are ubiquitous, with 2 hours of documentation spent for every hour of face-toface patient care in current primary care practice. ${ }^{34}$ In light of these existing time demands, progress toward additional, detailed office visit documentation will require EHR improvements allowing more facile documentation and retrieval of detailed social history. Innovative and automated EHR-based solutions that make it easier for providers to integrate social 
and emotional determinants of health into routine care may eventually link documentation practices to improved outcomes over time. Requirements of the Promoting Interoperability program make the development and adoption of such technologies even more acutely necessary. Furthermore, patients perceive that various social and emotional determinants, such as emotions, social life, social activities, and finances, should be documented in the EHR. ${ }^{35}$

Improving documentation among physicians through educational intervention has reaped little benefit, ${ }^{36}$ perhaps due to the lack of compelling incentives in an already timeconstrained clinical environment. To make measurable improvement, interventions must work to offset the burden of documentation, seamlessly integrate into current documentation workflows, or provide incentives for clinicians. Scribes (who document on behalf of the physician) have helped improve clinical efficiency in a team-based practice but more research needs to examine their potential role in improving the quality of documentation. While scribes may improve subjective quality of the documentation, studies have not assessed objective quality in diverse care settings, or consistency of documentation with the actual topics discussed in the encounter. ${ }^{37,38}$ Holding more promise, is addressing a potential contributing factor-the lack of incentives. While there is an evidence base for improvements in outcomes with the integration of a patient's social and emotional concerns in the form of patient-centered care, ${ }^{39-41}$ there are a lack of financial reimbursement mechanisms that would allow physicians to justify spending time on these important components. Recommendations and frameworks for the inclusion of social and behavioral data in the EHR, while a necessary start, do little to assign accountability for incorporating an assessment of these measures into the clinical encounter by the physician. ${ }^{42-44}$ Although insurance payments are increasingly linked to care that is defined as "patient-centered ${ }^{45}$," definitions of this concept vary and effectively do very little to improve the documentation and addressment of social and emotional elements. Policymakers must align incentives to promote enhanced documentation that results from the integration of social and emotional elements into primary care, which will further strengthen the doctor/patient relationship, a key element of the PCMH and new models of care such as the Comprehensive Primary Care Plus program. ${ }^{46,47}$ Future empirical research is needed to define the contributing factors for the lack of documentation of social/emotional topics relative to other health topics. Our study, while identifying a gap in documentation of occurring communication, does not attempt to identify the root cause.

This study has several important limitations. Due to the intensive nature of data collection and coding, study resources limited the collection of encounters beyond what was required for the qualitative analysis. Furthermore, our quantitative analysis was underpowered, resulting in the use of a nonparametric analysis. We include results from our quantitative analysis to demonstrate that pursuing larger, well-powered studies on the topic is an important area for future research. Additionally, this study is an assessment of EHR records and does not compare the documentation of social and emotional components of care between electronic and paper-based records, which may have provided an interesting comparative analysis as to whether or not the problem is resulting from the shift toward electronic documentation.

\section{Conclusion}

Treatment recommendations for patients with complex chronic disease must be made in the context of social and emotional factors. Given the importance of documentation for interdisciplinary team communication, absence of documentation concerning social determinants of health can adversely impact patient care. Placing systems, resources, and tools in the hands of clinicians may make it more feasible for them to disseminate important office visit communication about social and emotional factors impacting clinical care through EHR documentation. While many questions exist about how to develop, structure, and sustain these improvements, such health care investments have great potential to improve development of personalized care plans for vulnerable patients.

\section{Clinical Relevance Statement}

Clinicians routinely discuss social and emotional factors with patients to develop care plans. Systems' changes that promote feasibility of disseminating these conversations through EHR documentation can help improve the quality of interdisciplinary communication, especially during care transitions, such as hospital and specialty care, which are more often experienced by patients with complex, chronic disease. Innovative and automated EHR-based solutions, scribe solutions, as well as enhanced reimbursement mechanisms that make it easier for providers to act on certain social and emotional determinants of health should be explored and evaluated in research and quality improvement.

\section{Multiple Choice Questions}

1. Which of the following categories emerging from this study require more thorough documentation after discussion during an office visit?

a. Social and emotional factors.

b. Chronic disease.

c. Preventive care.

d. Acute/new problems.

Correct Answer: The correct answer is option a. In this study, we found that of 73 total "chronic conditions" topics, 66 (90.4\%) were documented in the encounter's corresponding progress note. A similarly high percentage of topics were documented in both the "acute/new problems" and "disease prevention" groups; results showed 16 out of $19(84.2 \%)$ and 8 out of $9(88.9 \%)$ discussions were documented in these categories, respectively. In contrast, of the 36 "social and emotional health" topics discussed, only 11 (30.6\%) of these details were documented in the corresponding progress note. 
2. The results of this study show that physicians are most likely to document the following type of information after discussing it with the patient:

a. Social and emotional factors.

b. Chronic disease factors.

c. Preventive care factors.

d. Acute/new problems.

Correct Answer: The correct answer is option b. The results of our study show that providers were most likely to document the results of conversations about chronic disease, a topic for which there was approximately $90.4 \%$ agreement between encounter transcripts and documentation in the EHR. Chronic disease was also the most discussed topic across all the clinical encounters and the topic discussed for the longest amount of time (on average) per encounter.

\section{Protection of Human and Animal Subjects}

This study was performed in compliance with the World Medical Association Declaration of Helsinki on Ethical Principles for Medical Research Involving Human Subjects, and was reviewed by The Ohio State University Institutional Review Board.

\section{Conflict of Interest}

None declared.

\section{References}

1 HIMSS. Electronic Health Records. 2018. Available at: https:// www.himss.org/library/ehr/\%3FnavitemNumber\%3D13261.

Accessed November 5, 2018

2 Kern LM, Barrón Y, Dhopeshwarkar RV, Edwards A, Kaushal R; HITEC Investigators. Electronic health records and ambulatory quality of care. J Gen Intern Med 2013;28(04):496-503

3 Wang SJ, Middleton B, Prosser LA, et al. A cost-benefit analysis of electronic medical records in primary care. Am J Med 2003;114 (05):397-403

4 McCullough JS, Christianson J, Leerapan B. Do electronic medical records improve diabetes quality in physician practices? Am J Manag Care 2013;19(02):144-149

5 Romano MJ, Stafford RS. Electronic health records and clinical decision support systems: impact on national ambulatory care quality. Arch Intern Med 2011;171(10):897-903

6 Russo R, Fitzgerald SP, Eveland JD, Fuchs BD, Redmon DP. Improving physician clinical documentation quality: evaluating two selfefficacy-based training programs. Health Care Manage Rev 2013; 38(01):29-39

7 Hollingsworth JC, Chisholm CD, Giles BK, Cordell WH, Nelson DR. How do physicians and nurses spend their time in the emergency department? Ann Emerg Med 1998;31(01):87-91

8 Poissant L, Pereira J, Tamblyn R, Kawasumi Y. The impact of electronic health records on time efficiency of physicians and nurses: a systematic review. J Am Med Inform Assoc 2005;12(05): 505-516

9 Miller RH, Sim I. Physicians' use of electronic medical records: barriers and solutions. Health Aff (Millwood) 2004;23(02): $116-126$

10 Joukes E, Abu-Hanna A, Cornet R, de Keizer NF. Time spent on dedicated patient care and documentation tasks before and after the introduction of a structured and standardized electronic health record. Appl Clin Inform 2018;9(01):46-53
11 Østbye T, Yarnall KSH, Krause KM, Pollak KI, Gradison M, Michener JL. Is there time for management of patients with chronic diseases in primary care? Ann Fam Med 2005;3(03): 209-214

12 Centers for Disease Control and Prevention. Leading Indicators for Chronic Diseases and Risk Factors. 2015. Available at: https:// chronicdata.cdc.gov/. Accessed January 10, 2019

13 Kripalani S, LeFevre F, Phillips CO, Williams MV, Basaviah P, Baker DW. Deficits in communication and information transfer between hospital-based and primary care physicians: implications for patient safety and continuity of care. JAMA 2007;297(08): 831-841

14 Elhauge E, ed. The Fragmentation of U.S. Health Care: Causes and Solutions. Oxford University Press on demand; 2010

15 Sinnott C, Mc Hugh S, Browne J, Bradley C. GPs' perspectives on the management of patients with multimorbidity: systematic review and synthesis of qualitative research. BMJ Open 2013;3(09):e003610

16 Stange KC. The problem of fragmentation and the need for integrative solutions. Ann Fam Med 2009;7(02):100-103

17 Zolnierek KB, Dimatteo MR. Physician communication and patient adherence to treatment: a meta-analysis. Med Care 2009;47(08):826-834

18 Sharma R, Kostis WJ, Wilson AC, et al. Questionable hospital chart documentation practices by physicians. J Gen Intern Med 2008;23 (11):1865-1870

19 Foy R, Hempel S, Rubenstein L, et al. Meta-analysis: effect of interactive communication between collaborating primary care physicians and specialists. Ann Intern Med 2010;152(04):247-258

20 Barnett K, Mercer SW, Norbury M, Watt G, Wyke S, Guthrie B. Epidemiology of multimorbidity and implications for health care, research, and medical education: a cross-sectional study. Lancet 2012;380(9836):37-43

21 McCabe C. Nurse-patient communication: an exploration of patients' experiences. J Clin Nurs 2004;13(01):41-49

22 Senteio C, Veinot T, Adler-Milstein J, Richardson C. Physicians' perceptions of the impact of the EHR on the collection and retrieval of psychosocial information in outpatient diabetes care. Int J Med Inform 2018;113:9-16

23 Guest G, Bunce A, Johnson L. How many interviews are enough? Field Methods 2006;18(01):59-82

24 Glaser BG, Strauss AL. The Discovery of Grounded Theory: Strategies for Qualitative Research. New York: Aldine Publishing; 1967

25 Pagano M, Gauvreau K. Principles of Biostatistics. Belmont, CA: Duxbury; 2000

26 StataCorp. Stata Statistical Software: Release 14. College Station, TX: StataCorp; 2015

27 Tariman JD, Doorenbos A, Schepp KG, Becker PS, Berry DL. Patient, physician and contextual factors are influential in the treatment decision making of older adults newly diagnosed with symptomatic myeloma. Cancer Treat Commun 2014;2(2-3): 34-47

28 Bodenheimer T, Chen E, Bennett HD. Confronting the growing burden of chronic disease: can the U.S. health care workforce do the job? Health Aff (Millwood) 2009;28(01):64-74

29 Cockerham WC, Hamby BW, Oates GR. The social determinants of chronic disease. Am J Prev Med 2017;52(1S1, Suppl 1):S5-S12

30 Recommended Social and Behavioral Domains and Measures for Electronic Health Records. 2014. Available at: http://nationalacademies.org/hmd/ /media/Files/Report Files/2014/EHR-phase2/EHRfindingsrecs.pdf. Accessed October 2018

31 CMS.gov. 2018 Program Requirements Medicare. 2018. Available at: https://www.cms.gov/Regulations-and-Guidance/Legislation /EHRIncentivePrograms/2018ProgramRequirementsMedicare. html. Accessed October 2018

32 Arcury TA, Quandt SA, Sandberg JC, et al. Patient portal utilization among ethnically diverse low income older adults: observational study. JMIR Med Inform 2017;5(04):e47 
33 Emani S, Ting DY, Healey M, et al. Physician beliefs about the impact of meaningful use of the EHR: a cross-sectional study. Appl Clin Inform 2014;5(03):789-801

34 Sinsky C, Colligan L, Li L, et al. Allocation of physician time in ambulatory practice: A time and motion study in 4 specialties. Ann Intern Med 2016;165(11):753-760

35 Prodinger B, Rastall P, Kalra D, Wooldridge D, Carpenter I. Documenting routinely what matters to people: standardized headings for health records of patients with chronic health conditions. Appl Clin Inform 2018;9(02):348-365

36 Fanucchi L, Yan D, Conigliaro RL. Duly noted: lessons from a twosite intervention to assess and improve the quality of clinical documentation in the electronic health record. Appl Clin Inform 2016;7(03):653-659

37 Misra-Hebert AD, Amah L, Rabovsky A, et al. Medical scribes: how do their notes stack up? J Fam Pract 2016;65(03):155-159

38 Walker KJ, Wang A, Dunlop W, Rodda H, Ben-Meir M, Staples M. The 9-Item Physician Documentation Quality Instrument (PDQI-9) score is not useful in evaluating EMR (scribe) note quality in Emergency Medicine. Appl Clin Inform 2017;8(03): 981-993

39 Stewart M, Brown JB, Donner A, et al. The impact of patient-centered care on outcomes in family practice. J Family Practice 2000;49(09): 796-804
40 Bertakis KD, Azari R. Patient-centered care is associated with decreased health care utilization. J Am Board Fam Med 2011;24 (03):229-239

41 Franks P, Tancredi DJ, Winters P, Fiscella K. Including socioeconomic status in coronary heart disease risk estimation. Ann Fam Med 2010;8(05):447-453

42 Adler NE, Stead WW. Patients in context-EHR capture of social and behavioral determinants of health. N Engl J Med 2015;372 (08):698-701

43 Gold R, Cottrell E, Bunce A, et al. Developing electronic health record (EHR) strategies related to health center patients' social determinants of health. J Am Board Fam Med 2017;30(04):428-447

44 DeVoe JE, Bazemore AW, Cottrell EK, et al. Perspectives in primary care: a conceptual framework and path for integrating social determinants of health into primary care practice. Ann Fam Med 2016;14(02):104-108

45 Epstein RM, Street RL Jr. The values and value of patient-centered care. Ann Fam Med 2011;9(02):100-103

46 Stange KC, Nutting PA, Miller WL, et al. Defining and measuring the patient-centered medical home. J Gen Intern Med 2010;25 (06):601-612

47 Sessums LL, McHugh SJ, Rajkumar R. Medicare's vision for advanced primary care new directions for care delivery and payment. JAMA 2016;315(24):2665-2666 